Case Report

\title{
Analysis of the Resilience of Common-Pool Resources during Globalization: The Case of Jeju Common Ranches in Korea
}

\author{
Kyungmin Kim, Juhee Kim, Kijong Cho, Jeong-Gyu Kim and Seunghun Hyun * \\ Department of Environmental Science and Ecological Engineering, Korea University, Seoul 02841, Korea; \\ km6354@korea.ac.kr (K.K.); 2003140144@korea.ac.kr (J.K.); kjcho@korea.ac.kr (K.C.); \\ lemonkim@korea.ac.kr (J.-G.K.) \\ * Correspondence: soilhyun@korea.ac.kr; Tel.: +82-2-3290-3068
}

Received: 9 October 2018; Accepted: 20 November 2018; Published: 22 November 2018

\begin{abstract}
A common-pool resource (CPR) is a type of good consisting of a natural or human-made resource system. Jeju common ranches are historical CPRs located in Jeju Province where mid-mountainous grassland has been shared for livestock farming by the members of adjacent villages since the 10th century. Because of the recent globalization movement, the number of ranches has decreased from 126 in the 1940s to only 53 in 2015; while the majority of the ranches did not survive the transformation, others have remained active by adopting various solutions. In this study, we analyzed the administrative characteristics of the CPRs to explain their current status (i.e., extinction or continuance as a common property) using logistic regression analysis. From this analysis, four statistically meaningful variables were extracted using a forward stepwise selection method; these include the type of ranch management, ratio of land area to population, number of internal committees in the village, and number of local government grants. These variables correlate well with previously recognized 'community resilience dimensions' and can be used to explain the fate of the Jeju common ranches during the study period. This study elucidates what community dimensions should be fortified to promote the resilience of Jeju common ranches in order to effectively cope with the on-going effects of globalization.
\end{abstract}

Keywords: community resilience; common-pool resource; globalization; Jeju common ranch

\section{Introduction}

\subsection{Previous Resilience Studies}

During the last few decades, the concept of resilience has been employed and implemented in a wide range of academic areas including ecology, psychology, economics, and sociology. In a general sense, resilience is defined as the capacity of a system to absorb disturbance without changing its major function and structure [1] even though the scale and characteristics of the 'system' may differ depending on the area of study. In the literature, the concept of resilience was developed via two paths of study [2]. One path originated from ecology and focusses on the adaptive relationships in integrated social-ecological systems (SESs) in which the social and ecological components are coupled and interdependent; these studies are known as SES level studies. The other path originated from psychology in the areas of personal development and mental health in which a cognitive understanding of the adaptive capacity of people is pivotal; these studies focus on the identification and development of an individual's ability to cope with disturbance and are known as individual level studies.

The definitions of resilience that emerged from these two origins have a common focus on the adaptive capacity of a system (e.g., individuals, large societies, ecosystems, or social-ecological systems) 
in the face of disturbance. Recently, the two paths have converged toward local or community-level resilience, which has been relatively neglected over the last few decades. Community resilience has been defined as the existence, development, and engagement of community resources by members of the community to thrive in environments characterized by change and uncertainty [3]. After reviewing numerous literature publications and case studies, eight community resilience dimensions are proposed here that that describe community resilience as actionable, observable, and measurable quantities. These eight dimensions are as follows: community resources, development of community resources, engagement of community resources, active agents, collective action, strategic action, equity, and impact. If a community is resilient, the members intentionally develop personal and collective capacity that they engage to respond to and influence change, sustain and renew the community, and develop new trajectories for the future of the community [4].

A common dilemma being addressed by numerous researchers is an example of a community resilience study [5]. In this case, a common dilemma is a decision situation that recreates a dilemma connected with harvesting common-pool resources (CPRs) in which the decision of each member affects the outcomes of others. The situation enables individuals to choose between something that favors their own benefit versus something that will be beneficial the whole community. Common-pool resources are often owned and managed by the local community as a common-property system. Examples of CPRs are man-made irrigation systems, fishing grounds, groundwater basins, forests, and pastures. Unlike purely public goods, the continued existence of a CPR can be threatened when the potential benefit of its maintenance diminishes.

The transformation of a CPR can be investigated by analyzing the various characteristics of the associated community including governance structure, decision-making processes, and cooperative action; all of these are essentially related to the attitude of a community member toward the natural resource system. Therefore, it can be stated that the resilience of a CPR is an intermediate scale research subject in which the attitudes of the individuals of the community in confronting transformation pressure will determine the fate of the CPR. Community resilience is an essential part of the sustainability of a larger scale system since the community is a group of people who affect the stability of the SES through their interactions.

In Korea, many man-made resource (or community) systems have been disturbed upon facing the transformative pressures that occurred since the beginning of industrialization in the middle of the 20th century. However, to date, very few studies have been conducted on the resilience of the resource systems in Korea. One exception is the work done by Yu et al. [6] that investigated the transformation of the Songgye community forest under the pressure of globalization. The community forest is a self-governed CPR located in the Geumsan area from which local community members obtain benefits through cooperative management. In their study, the size of the community and network diversity of the community members were identified as the primary factors determining the fate of natural resources under transformative pressure.

\subsection{Research Scope}

As a case study of the resilience of a traditional CPR system in Korea, the objectives of this work are as follows: (i) to review the literatures of the Jeju common ranches as CPRs and (ii) to evaluate the response of the ranch system to external disturbance by analyzing the administrative record between 2003 and 2015. Among the various types of disturbances, the globalization movement that began at the beginning of the 21st century was selected as a major driver of transformation pressure on the Jeju common ranches. This has had a significant impact on determining whether or not the ranches have continued to function as CPRs for the local community. The focus was placed on understanding the properties of this system that relate to successful transformation and that have enabled some of the ranches to survive as a CPR. The competition variables that may affect the resilience of CPRs if coexisting [7] were not accounted for in this work. 


\section{Methods}

\subsection{Geographic Description of the Study System}

The subjects of this study, i.e., the Jeju common ranches, are located in the Jeju Province, which is the largest island off the south coast of the Korean Peninsula with the coordinates $126^{\circ} 08^{\prime} 38^{\prime \prime}-126^{\circ} 58^{\prime} 22^{\prime \prime}$ for the eastern longitude and $33^{\circ} 06^{\prime} 36^{\prime \prime}-34^{\circ} 00^{\prime} 46^{\prime \prime}$ for the northern latitude (Figure 1). Jeju Island comprises an area of $1849.1 \mathrm{~km}^{2}$, measuring $73 \mathrm{~km}$ across east-to-west and $41 \mathrm{~km}$ from north-to-south. The landscape is dominated by Halla Mountain, a dormant volcano in the center of the island (1950 $\mathrm{m}$ above sea level), that features an altitudinal distribution of ecosystems including a coastal district (0-200 m above sea level), mid-mountainous district (200-600 m above sea level), and intermountain district (>600 $\mathrm{m}$ above sea level). The three altitudinal districts are characterized by their landscapes, which are dominated by seaside villages, grassland, and forests, respectively. The Jeju common ranches are located in the mid-mountainous district. Jeju Island has both a subtropical and temperate climate with moderate temperatures and high rainfall. The temperature rarely falls below $0{ }^{\circ} \mathrm{C}$, even in the winter, with an annual mean temperature of $15-16^{\circ} \mathrm{C}$, and the annual precipitation is approximately 1300-2000 $\mathrm{mm}$ [8].

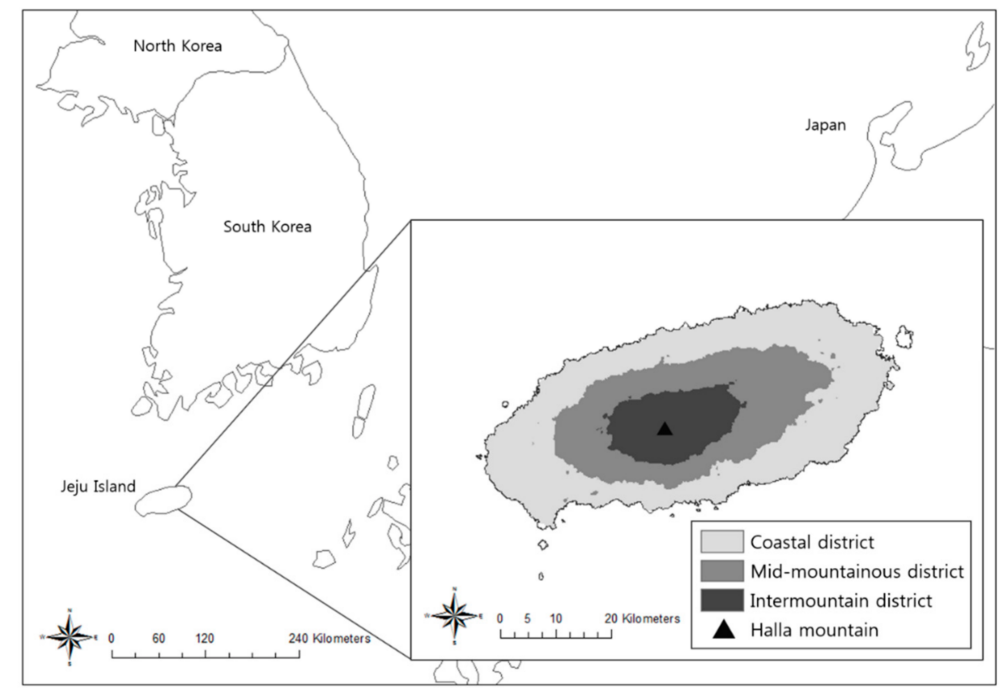

Figure 1. Geographic location of the Jeju Province (Island) in the Korean Peninsula. The altitudinal distribution of ecosystems from the ocean side is characterized as the coastal (0-200 m above sea level), mid-mountainous (200-600 m above sea level), and intermountain ( $>600 \mathrm{~m}$ above sea level) districts, respectively. Halla Mountain (1950 m), a dormant volcano, is in the center.

\subsection{Research Assumptions}

To analyze the resilience of the common ranch system, several assumptions were made. Firstly, to exclude the impact of other disturbances, globalization was considered to be the only disturbance imposed on the ranches in the 2000s. Each common ranch was presumed to experience equivalent pressure from globalization; this assumption is acceptable because of the shared geographical, political, historical, cultural, and climatic backgrounds of the common ranches on Jeju Island. Thus, the fundamental drivers for determining the continuance/extinction of CPRs were assumed to be their inherent characteristics, which are called 'system variables'. Secondly, different common ranches have different levels of system variables, and the magnitude of these variables subsequently affects the resilience capacities of the common ranches. Thus, we hypothesized that a common ranch system becomes extinct when the transformation pressure exceeds its resilience capacity. To test this, we also assumed that the resilience of 75 cases of common ranches are well reflected in the administrative record and thus the outcome of transformation can be assessed through the combination of these data. 


\section{Data Collection and Analysis}

\subsection{Data Collection and Description}

To investigate the historical development and roles of the Jeju common ranches, literature data were collected and examined. According to the historical literature, the ranches first appeared during the 12th century during the Kyoro Dynasty as a form of state-owned ranch. The agricultural, ecological, and sociological implications of the Jeju common ranches for the local community were analyzed to understand the transformation of their structure and function within the context of their subsequent historical development.

For statistical analysis, the administrative data of the common ranches and associated village were obtained from the office of the Jeju Province; these data included the sizes of the ranches, management types of the ranches, governance structure of the village assembly council, village population, and number of livestock. Unfortunately, many of the administrative records for the common ranches were lost during the Japanese colonial era (1910-1945) and Korean War (1950-1953). In 2003, the local government conducted a fact-finding survey that resulted in new data filings on the 75 common ranches throughout the Jeju Province. These data were analyzed to extract a statistically meaningful subset dataset, and the following eight variables were identified: type of ranch management $\left(X_{1}\right)$, number of participating villages $\left(X_{2}\right)$, ratio of ranch area to population $\left(X_{3}\right)$, number of internal committees under the village council $\left(X_{4}\right)$, number of public facilities $\left(X_{5}\right)$, number of village festivals $\left(X_{6}\right)$, number of grants from the local government $\left(X_{7}\right)$, and fraction of state-owned land area $\left(X_{8}\right)$. Here, $X_{1}, X_{2}, X_{3}, X_{6}, X_{7}$, and $X_{8}$ were obtained from the continuous data that were collected between 2003 and 2015. Data for variable $X_{4}$ and $X_{5}$ were extracted from the 2015 annual report from the office of Jeju Province. Analysis of multicollinearity between the eight datasets was not performed in this work.

\subsection{Statistical Analysis: Logistic Regression Model}

Binominal logistic regression is used to test hypotheses regarding relationships with a dichotomous outcome (e.g., pass or fail) and predictor variables (either categorical or continuous) [9]. Among the 75 common ranches that were present in 2003, 22 ranches (29.3\%) cease to exist while 53 ranches $(70.7 \%)$ are currently active. The research hypothesis tested using these data was as follows: the likelihood of the continuance of a common ranch is related to all/part of its community characteristics. Thus, the outcome was set to two values, i.e., 0 and 1 , which correspond to the ranch ceasing and continuing to exist, respectively. The mean and standard deviation of the continuous variables (i.e., $X_{2}, X_{3}, X_{4}, X_{5}$, $X_{6}, X_{7}$, and $\left.X_{8}\right)$ and the ranch numbers for each category of categorical variable $\left(X_{1}=0,1\right.$, or 2$)$ are shown in Table 1.

Table 1. Numerical ranges of the eight variables used for logistic regression.

\begin{tabular}{|c|c|c|c|c|c|c|c|c|c|c|c|}
\hline \multirow{3}{*}{$\begin{array}{l}\text { Current } \\
\text { Status }\end{array}$} & \multirow{3}{*}{$\begin{array}{c}\text { Sample } \\
\text { Size }\end{array}$} & \multirow{2}{*}{\multicolumn{3}{|c|}{$\begin{array}{c}\text { Categorical Variable }^{\mathrm{a}} \\
\mathrm{X}_{1} \\
\end{array}$}} & \multicolumn{7}{|c|}{ Continuous Variable ${ }^{b}$} \\
\hline & & & & & $X_{2}$ & $X_{3}$ & $X_{4}$ & $X_{5}$ & $x_{6}$ & $x_{7}$ & $X_{8}$ \\
\hline & & $\begin{array}{c}0 \\
\text { (Open) }\end{array}$ & $\begin{array}{c}1 \\
\text { (Rent) }\end{array}$ & $\begin{array}{c}2 \\
\text { (Direct) }\end{array}$ & \multicolumn{7}{|c|}{ Mean Value (Standard Deviation) } \\
\hline Continuance & 53 & 4 & 17 & 32 & $\begin{array}{c}1.24 \\
(0.66)\end{array}$ & $\begin{array}{c}2.38 \\
(2.44)\end{array}$ & $\begin{array}{c}6.71 \\
(2.78)\end{array}$ & $\begin{array}{c}4.40 \\
(2.46)\end{array}$ & $\begin{array}{c}4.00 \\
(3.82)\end{array}$ & $\begin{array}{c}1.05 \\
(1.43)\end{array}$ & $\begin{array}{c}1.51 \\
(6.11)\end{array}$ \\
\hline Extinction & 22 & 6 & 7 & 9 & $\begin{array}{c}1.35 \\
(0.86)\end{array}$ & $\begin{array}{c}1.36 \\
(0.10)\end{array}$ & $\begin{array}{c}5.94 \\
(2.02)\end{array}$ & $\begin{array}{c}4.12 \\
(1.90)\end{array}$ & $\begin{array}{c}3.06 \\
(2.22)\end{array}$ & $\begin{array}{c}0.12 \\
(0.49)\end{array}$ & $\begin{array}{c}0.65 \\
(2.67)\end{array}$ \\
\hline Sum & 75 & 10 & 24 & 41 & $\begin{array}{c}1.27 \\
(0.72)\end{array}$ & $\begin{array}{c}2.09 \\
(2.17)\end{array}$ & $\begin{array}{c}6.49 \\
(2.59)\end{array}$ & $\begin{array}{c}4.32 \\
(2.30)\end{array}$ & $\begin{array}{c}3.73 \\
(3.44)\end{array}$ & $\begin{array}{c}0.78 \\
(1.30)\end{array}$ & $\begin{array}{c}1.26 \\
(5.34)\end{array}$ \\
\hline
\end{tabular}

${ }^{a}$ For the categorical variables, $X_{1}=$ type of ranch management; 'open' for open to public, 'rent' for rental operation, and 'direct' for direct operation. ${ }^{b}$ For continuous variables, $\mathrm{X}_{2}=$ number of participating villages per ranch, $\mathrm{X}_{3}=$ ratio of land area to population number, $\mathrm{X}_{4}=$ number of internal committees under the village council, $X_{5}=$ number of public facilities, $X_{6}=$ number of village festivals, $X_{7}=$ number of grants from the local government, and $\mathrm{X}_{8}=$ fraction of state-owned land area. 
The simple logistic model used in this study is

$$
\operatorname{Logit}(Y)=\operatorname{Ln}(\text { odds })=\operatorname{Ln}(p /(1-p))=a+\sum b_{i} X_{i}
$$

where $p$ is the probability $\left(p=e^{a+\sum b_{i} X_{i}} /\left(1+e^{a+\sum b_{i} X_{i}}\right)\right), Y$ is the outcome of interest, $X$ is a specific value of $X, i$ is the selected variable number, and $b$ is the regression coefficient. The logistic regression analysis was performed using $\mathrm{YBM}^{\circledR}$ SPSS $^{\circledR}$ Statistics 23.0 on Windows 10 . The eight predictor variables were input using a forward selection method $\left(P_{\text {in }}=0.15, P_{\text {out }}=0.10\right.$, cut $\left.=0.55\right)$. The statistical significance of the individual regression coefficients (i.e., $b_{i}$ in the simple logistic model) was tested using the Wald chi-square test. Overall, the fit of the model prediction with the actual outcome was evaluated using the Hosmer-Lemeshow test.

\section{Results}

\subsection{Historical Development of the Jeju Common Ranches}

As a form of organized association, Jeju common ranches began in the 1920s [10]. Historically, it was well documented that a Jeju common ranch is an extension of the state ranch system, which was initially formed during the Koryo Dynasty (918-1392) and retained during the Chosun Dynasty (1392-1910). By that time, there were 10 divisions of state-owned ranches across the mid-mountainous district of Jeju Island [10-12]. The ranches were primarily utilized to supply army horses; however, the ranches could also be used as grazing land for private horses owned by locals. In the 1870s, the state ranches were closed because of the reduction in demand for horses as a result of changing politics and warfare. Subsequently, the formerly state-owned land was divided into small sectors and granted to nearby villages. Since then, any village member could graze their livestock (e.g., horses and cows), which was essential for agriculture at that time. Some portion of the land was cultivated for crop production. During this period, a 'common ranch association' was voluntarily organized by villagers to ensure that the common resource was shared equitably. Although the association was not codified, it represented the initial form of a self-governed system for the management and utilization of common resources among local community members.

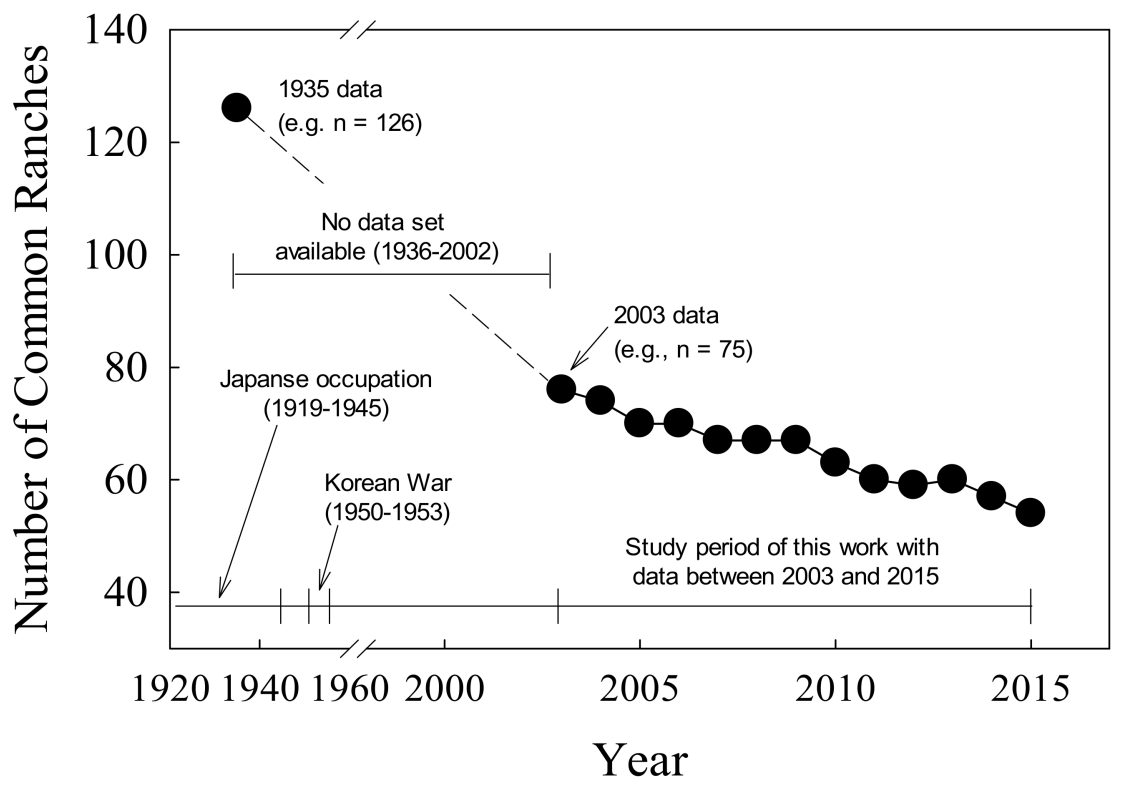

Figure 2. Temporal changes in the number of Jeju common ranches since the 1930s. The historical periods of Japanese control and the Korean War are also shown. 
The traditional form of a community-based resource system was significantly disturbed by the Japanese occupation of this area from 1910 to 1945. The common ranch was transformed in compliance with the exploitative demands of Japanese militarism [10]. During this period, the land management ordinance was enforced, and the administrative boundaries of the common ranches were established. The ownership of the common ranches was forcibly vested to selected village members, and the documented owners were required to supply army horses and meat for the Japanese military $[10,12,13]$. According to Kang [10], there were 126 common ranches in this area in the 1930s (Figure 2). However, most of the administrative records for the common ranches were intentionally or accidently destroyed during Japan's Pacific War and the Korean War.

\subsection{Structure and Function of the Common Ranches}

As stated earlier, Jeju common ranches have been utilized as public infrastructure for locals for over 1000 years. The ranches comprise grassland and are located in the mid-mountainous district of Jeju Province. The ranches have been maintained as a self-governed social system for village residents that involved collaborative labor, resource sharing, and collective decision making. Based on the analysis of literature and administrative data, the common ranches performed the following three major functions.

First, they provided ecological services for Jeju Province. The ecological and climatic suitability for raising livestock led to the establishment of ranches throughout the mid-mountainous district. This district generally comprises flat grassland with relatively low temperatures in the summer, which is favorable for pasture livestock because it prevents ticks, which impede livestock growth. Being located at an intermediate altitude covered by short bushes and grasses, the ranches have also played an important role as an ecological transition buffer zone, connecting the coastal and mountain districts. In addition, the mid-mountainous district is also a groundwater recharge zone in which rainwater is routed to the subsurface. Groundwater recharge is an important process for sustainable groundwater utilization for most villages along the coastal district of Jeju Province.

Secondly, the common ranches have provided public services for the local communities. The ranches are a common place for village members to graze their cows and horses, which is essential for agricultural labor. In addition, public goods, such as livestock manure for compost manufacturing and bush wood for firewood, are also supplied by the common ranch system.

Lastly, the ranches fortified social unity and were an important part of maintaining the culture of the associated village through the collective activity required for ranch management. Village members voluntarily organized a common ranch association to share the common resources and regulate overexploitation of resources. For instance, dozens of livestock owners formed joint labor groups through which each member was designated a time period for guarding the grazing livestock over the summer. Also, members sometimes helped each other during the cropping season. Unauthorized practices were prohibited by the association's rules, although neither the association nor land ownership was codified.

\subsection{Driver of Transformation: Globalization}

Globalization is a process of international integration that generates an interdependence of economy, cultural activities, and everyday life [14]. Even though there are a variety of opinions on when globalization began, it is generally accepted that it began, at the earliest, after World War II. Likewise, Korea experienced a dramatic change in its political system and rapid economic growth by the 1970s as a result of globalization. This resulted in Korea being termed a 'newly industrializing country' in Asia, and a wide variety of export-related industries have since flourished. As global free-trade progressed, the activities of domestic corporations expanded overseas, and, concurrently, transnational corporations began operating within the country. Korea's dependency on other countries intensified after the 1990s because of the economic reconstruction required to overcome the financial crisis. This recovery was supported by the International Monetary Fund, leading to transnational 
capital becoming increasingly dominant. The impact of early globalization (1970-1990) on the Jeju common ranches was not investigated in this work because of a lack of associated records.

A new era of globalization occurred in the 21st century because of the emergence of new communication technologies and transportation infrastructure. As a result, globalization brought deeper interconnectedness and spatial expansion throughout the world, enhancing the interdependency of all regions $[15,16]$. As the new globalization era began in the 2000s, many common ranches failed to maintain their structures and functions as the transformation pressure overwhelmed their resilience capacity. The impact of globalization on the Jeju common ranches can be attributed to the following: (i) the inflow of substitute goods and services from other regions; (ii) conversion from primary to tertiary industry; and (iii) the desire for development and the dramatic rise of the economic value of the terrain where the common ranches are located. These changes attenuated the resource dependency of the common ranch as the demand for the use of grassland for livestock farming declined. Fodder had been imported into Korea as a substitute for domestic hay grown from the local grassland, thereby reducing the importance of the common ranch as a food source for livestock. Furthermore, by that time, the industrial structure in Jeju Province had changed from an initial focus on primary industries, such as livestock farming, to tertiary industries, such as tourism and leisure. Although there are many community members who remain engaged in primary industry and who rely on village-based common ranches, large-scale capital-intensive ranches operated by conglomerate companies in pursuit of agricultural capitalism became dominant. Moreover, the value of the mid-mountainous district as a real-estate commodity sharply increased due to the increased investment in the leisure industry and tourism-promotion projects of the local government in the early 2000s. Subsequently, the transfer of ownership of the land to capitalist developers reduced the importance of the ranch system.

\subsection{Logistic Regression Model Fit}

The logistic regression model fit is

Predicted logit of $($ Continuance $)=-3.480+0.691 X_{1}+0.508 X_{3}+0.300 X_{4}+1.572 X_{7}$.

The logistic model was more effective than the null model, as assessed using the likelihood ratio $\chi^{2}$ test $\left(\chi^{2}=19.974, \alpha=0.001\right)$. The results of the goodness of the fit assessed by the Hosmer-Lemeshow inferential test $\left(\chi^{2}=2.342, \mathrm{df}=8, p>0.05\right)$ support the legitimacy of the regression model.

The statistical significances of the individual explanatory variables (i.e., $b_{i}$ in the simple logistic model) are presented in Table 2. According to the result of the Wald chi-square test, the log of the odds of existence is positively related to the number of internal committees in the village $\left(X_{4}, p<0.05\right)$ and the number of grants from the local government $\left(X_{7}, p<0.05\right)$. The type of ranch management $\left(X_{1}, p=0.140\right)$ and ratio of area to population in the village $\left(X_{3}, p=0.085\right)$ also showed acceptable levels of significance.

Table 2. Wald chi-square test ${ }^{a}$ of individual predictors of the logistic regression model fit.

\begin{tabular}{ccccccc}
\hline & Predictor & $\mathbf{B}^{\mathbf{b}}$ & $\mathbf{S E}^{\mathbf{c}}$ & Wald $^{\mathbf{d}}$ & Df $^{\mathbf{e}}$ & Sig. $^{\mathbf{f}}$ \\
\hline $\mathrm{X}_{1}$ & Type of ranch management & 0.691 & 0.469 & 2.174 & 1.000 & 0.140 \\
$\mathrm{X}_{3}$ & Ratio of land area to population number & 0.508 & 0.296 & 2.959 & 1.000 & 0.085 \\
$\mathrm{X}_{4}$ & Number of internal committees under the village council & 0.300 & 0.148 & 4.101 & 1.000 & 0.043 \\
$\mathrm{X}_{7}$ & Number of grants from local government & 1.572 & 0.662 & 5.645 & 1.000 & 0.018 \\
$\mathrm{C}$ & Constant & -3.480 & 1.483 & 5.509 & 1.000 & 0.019 \\
\hline
\end{tabular}

${ }^{\text {a }}$ Estimation was terminated at iteration number six because parameter estimates changed by less than 0.001 . All statistics reported herein are reported to three decimal places to maintain statistical precision. ${ }^{\mathrm{b}}$ Constant. ${ }^{c}$ Standard error. ${ }^{d}$ Wald chi-square test. ${ }^{e}$ Degree of freedom. ${ }^{f}$ Significant level.

The magnitude of sensitivity (94.9\%) was relatively high compared to that of specificity $(59.1 \%)$ (Table 3). The number of ranches that continued to run (53) was greater than the number that ceased 
to exist (22); this imbalance makes the model more suitable for predicting the cases of continuance. The false positive rate, i.e., the proportion of observations misclassified as events over all of those classified as events, was $14.3 \%$, and the false negative rate, i.e., the proportion of observations misclassified as nonevents over all of those classified as nonevents, was $35.3 \%$. The overall rate of correct prediction was $77.3 \%$.

Table 3. Comparison of model prediction and current status of 75 Jeju common ranches.

\begin{tabular}{cccc}
\hline & \multicolumn{3}{c}{ Model Result } \\
\hline \multirow{2}{*}{ Current Status (Observed Number) } & \multicolumn{2}{c}{ Predicted Number } & \multirow{2}{*}{ Accuracy Percentage (\%) } \\
\cline { 2 - 3 } & Continuance & Extinction & 94.9 \\
Continuance (53) & 45 & 8 & 59.1 \\
Extinction (22) & 9 & 13 & 77.3 \\
\hline
\end{tabular}

\section{Implications of the Four System Variables}

Four of the variables were found to be statistically significant for determining the binary outcomes (i.e., whether or not the ranch continued to exist in the logistic model); these included the type of ranch management $\left(X_{1}\right)$, ratio of area to population of the village $\left(X_{3}\right)$, number of internal committees under the village council $\left(X_{4}\right)$, and number of local government grants $\left(X_{7}\right)$ (Table 2$)$. The implications of these four system variables on the previously defined community resilience dimensions $[3,6]$ are as follows.

\subsection{Type of Ranch Management}

The type of ranch management $\left(X_{1}\right.$, a categorical variable) can be classified as direct (2), rent (1), and open (0) (Table 1). Direct ranch management indicates that the ranch is operated by the village, which means that most of the village members participate in the ranch management. The rent type of ranch management means that the village rents the common ranch land to an individual or a small number of village members who want to use the land. Due to the inflow of forage substitutes and industrial structural changes, the number of livestock farmers has declined. In the case of the rent management category, most of the village members agree to rent the land with payment. The open form of ranch management indicates that the common ranch area is open to the public, including outside communities. In this case, the common ranch land is inadequately managed or most of the village members are not interested in its management. The model results suggest that directly-managed ranches showed better resilience capacity because most village members are (either directly or indirectly) involved in their management. Therefore, they are willing to conserve their ranches because they dependent on the land and natural resources they provided. In contrast, the villages that adopt the rent or open management systems are vulnerable to disposal by ownership transfer, which leads to extinction of the common ranch because only a few village members are willing to conserve it; the ranch loses its importance for those who do not intend to farm livestock. Based on this context, it can be concluded that, in accordance with the results reported by Magis [3], the type of ranch management reflects the degree of community member engagement with the community resources.

\subsection{Ratio of Land Area to Population of the Village}

The ratio of land area to population of the village $\left(\mathrm{X}_{3}\right)$ is indicative of the number of resources that could potentially be assigned to individual community members. The positive correlation between the persistence of common property with its size per community member may be explained by the observation that community members associated with a large-scale ranch are supportive of maintaining the ranch as a common property, even though legal land ownership is not granted to them. Similar to 
the case of ranch management, this system factor is more likely related to each member's engagement in the community resources.

\subsection{Number of Internal Committees under the Village Council}

The number of internal committees in the village $\left(\mathrm{X}_{4}\right)$ indicates the degree of redundancy and diversity of decision-making pathways. Village members are voluntarily affiliated with various subordinate associations depending on their age, gender, social status, and hobbies. A wide range of groups in pursuit of divergent interests favors resilient decision making. As noted by Yu et al. [6], the network diversity between community members is one of the primary factors that determines the fate of community-based natural resources. In addition, the collective activities through the diverse sub-levels of an organization help build confidence among all village members. Confidence is a measure of the extent to which members of a community are assured that other members will honor their agreements regardless of their immediate interest [17]. Highly confident community members can be active agents leading to novel and cooperative decision making. Thus, it can be envisaged that a village with more internal committees has better communication leading to improved rates of collective action; these are both essential for developing the capacity for community resilience.

\subsection{Number of Local Government Grants}

The number of grants received from the local government of Jeju Province $\left(X_{7}\right)$ had the greatest impact on the continued existence of the ranches of the eight variables investigated in this study (i.e., $\exp (B)=4.817$, Table 2). The local government of Jeju Province has been granting subsidies for various community festivals organized by the village. To be eligible for a government grant, village leaders must apply for the subsidy with a well-organized festival proposal. To do this, the village council should have an efficient network to communicate with all of the village members. For beneficiary villages, the leader can be regarded as an active agent of good decision making. In addition, since matching funds $(50 \%)$ must be provided to obtain the subsidy, the village must be financially stable prior to the grant application. The common interest of the village members in managing their common property and in the stability of village finances seems to be a strong system characteristic that promote resilience. Therefore, in the case of common ranches in Jeju Province, the number of grants received from local government is most highly associated with two community dimensions, i.e., active agents and collective action, as noted by Magis [3].

\section{Conclusions}

The binary transformation patterns (i.e., continuance or extinction) of Jeju common ranches under the pressure of globalization were described by a combination of system variables extracted from the associated communities between 2003 and 2015. It was found that four system properties of 75 cases of CPRs, specifically the type of ranch management $\left(X_{1}\right)$, ratio of area to population $\left(X_{3}\right)$, number of internal committees $\left(X_{4}\right)$, and number of local government grants $\left(X_{7}\right)$, show statistical significance (collectively) for determining the outcome of the transformation. The result of regression signifies the administrative characteristics of resilient communities, such as engagement of natural resources, network diversity, and collective action among community members. Therefore, the results of this work can be adopted by policymakers to predict the impact of new policies on the sustainability of the Jeju common ranch system. It can be also used by associated community members to collaboratively determine their decisions on sustaining common ranches. Lastly, even though the generalization of findings from this work might be constrained to the case of Jeju common ranches, the results could be helpful for understanding the characteristics of other CPRs in Korea.

Author Contributions: Conceptualization, K.K. and S.H.; Investigation, K.K. and J.K.; Data Curation, K.K. and J.K.; Data Analysis, K.K. and J.C.; Writing, K.K. and S.H.; Resources, J.-G.K.; Supervision, S.H.

Funding: This research received no external funding. 
Acknowledgments: This research was funded in part by OJERI (O-Jung Eco-Resilience Institute) preliminary research project and in part by a Korea University Grant.

Conflicts of Interest: The authors declare no conflict of interest.

\section{References}

1. Holling, C.S. Resilience and stability of ecological systems. Annu. Rev. Ecol. Syst. 1973, 4, 1-23. [CrossRef]

2. Berkes, F.; Ross, H. Community resilience: Toward an integrated approach. Soc. Nat. Resour. 2013, 26, 5-20. [CrossRef]

3. Magis, K. Community resilience: An indicator of social sustainability. Soc. Nat. Resour. 2010, 23, 401-416. [CrossRef]

4. Norris, F.H.; Stevens, S.P.; Pfefferbaum, B.; Wyche, K.F.; Pfefferbaum, R.L. Community resilience as a metaphor, theory, set of capacities, and strategy for disaster readiness. Am. J. Community Psychol. 2008, 41, 127-150. [CrossRef] [PubMed]

5. Poteete, A.R.; Ostrom, E. Heterogeneity, group size and collective action: The role of institutions in forest management. Dev. Chang. 2004, 35, 435-461. [CrossRef]

6. Yu, D.J.; Anderies, J.M.; Lee, D.; Perez, I. Transformation of resource management institution under globalization: The case of songgye common forests in South Korea. Ecol. Soc. 2014, 19, 2. [CrossRef]

7. Ostrom, E.; Gardner, R.; Walker, J.; Walker, J. Rules, Games, and Common-pool Resources; University of Michigan Press: Ann Arbor, MI, USA, 1994.

8. Korea Ministry of the Interior and Safety. Survey on the Characteristics of Community Villages in Jeju Province; KMOIS: Seoul, Korea, 2015. Available online: http:/ / prism.go.kr/ (accessed on 30 September 2018).

9. Peng, C.-Y.J.; Lee, K.L.; Ingersoll, G.M. An introduction to logistic regression analysis and reporting. J. Educ. Res. 2002, 96, 3-14. [CrossRef]

10. Kang, M.I. A study on the cooperative pasture construction process in the 1930s in Jeju Island. Tamla Cult. 2008, 32, 75-136.

11. Yun, S.-J. Dissolving process of village pasture commons in Jeju Island and its social and ecological implication. Rural. Soc. 2006, 16, 45-88.

12. Choe, H. Redefining common pool resource and the case of common meadows in Jeju Island. Econ. Soc. 2013, 98, 12-39.

13. Bae, B. Historical study on the rise and change of the ownership of villagers' property. Kyungpook Natl. Univ. Law J. 2016, 53, 269-297.

14. Albrow, M.; King, E. Globalization, Knowledge and Society: Reading from International Society; SAGE Publications: Thousand Oaks, CA, USA, 1990.

15. Young, O.R.; Berkhout, F.; Gallopin, G.C.; Janssen, M.A.; Ostrom, E.; van der Leeuw, S. The globalization of socio-ecological systems: An agenda for scientific research. Glob. Environ. Chang. 2006, 16, 304-316. [CrossRef]

16. McMichael, P. Development and Social Change: A Global Perspective; Sage Publications: Thousand Oaks, CA, USA, 2016.

17. Basurto, X.; Gelcich, S.; Ostrom, E. The social-ecological system framework as a knowledge classificatory system for benthic small-scale fisheries. Glob. Environ. Chang. 2013, 23, 1366-1380. [CrossRef]

(C) 2018 by the authors. Licensee MDPI, Basel, Switzerland. This article is an open access article distributed under the terms and conditions of the Creative Commons Attribution (CC BY) license (http://creativecommons.org/licenses/by/4.0/). 